\title{
COPING STRATEGIES AS DETERMINANTS OF READINESS FOR AGE-RELATED CHANGES
}

https://doi.org/10.37096/SHDISJ-19-1.1-0012

Zuyeva Alyona,

https://orcid.org/0000-0002-3944-81123

\begin{abstract}
The article analyzes the topical matter of psychological mechanisms of awareness by person of own age. The problem is considered through study of relationship between the coping and subjective willingness to adopt age-related changes throughout the life. The aim of the article was to study features of the coping strategies as determinants of psychological readiness for age-related changes adoption in people of various ages (19-85 years old). Four hundred three inhabitants of four regions of Ukraine were surveyed, involving: 95 persons - inhabitants of the Southern Ukraine (23.6\%), 100 persons - residents of the Eastern Ukraine (24.8\%), 108 persons - residents of the Central Ukraine (26.8\%), 100 persons residents of the Western Ukraine (24.8\%). The method of readiness for age-related changes (N.S. Gluhanyuk, T.B. Gershkovich) and the SACS coping questionnaire (S. Hobfoll with co-authors) were used. It was found that components and levels of readiness for age-related changes adoption are determined by a number of coping strategies that are characterized by the prosocial coping vector, which is guided by future-oriented processes. It was shown that the coping has the most important value in formation of readiness for age-related changes adoption at the age under 35 years old. During this age period, the strategies activation of making social contact, search for social support, as well as the avoidance strategies suppression, play the most important role in integral readiness provision. The basic assumption of the research was confirmed related to the coping strategies as determinants of psychological readiness for age-related changes adoption. The fact determined in our research related to the avoidance coping strategies, as negative predictor of readiness for age-related changes adoption, corresponds to the data that acceptance of thoughts of aging intensifies and stabilizes the experience of transformational aging. The idea, debated in literature, of proactive and anticipatory-preventive attitude towards age-related changes adoption, which enables the efficient coping of age-related changes, was also confirmed in the research performed.
\end{abstract}

Keywords: age-related changes, social attitude, subjective readiness, coping strategies, senior people.

\section{Introduction}

Human aging is very important process, since it affects all aspects of human life, while modern researches of psychological aspects of aging are few and usually related to individual psychological processes and properties. According to M.K. Kremenchutska (2015), consideration of the problem of psychological support of a senior person is relevant in practical terms; and, therefore, a special organization is required of psychological support of senior people both of preretirement and retirement age, while the work of psychologist can be based on personal characteristics of the senior person.

So, considering the aging process as a natural one, it is necessary, however, to develop methods of managing it in order to prolong the period of active, adequate, employable life of a person, while shortening a relative proportion of years of decrepitude, improving in such a way the quality of life (Voroshilova, 2008). One of the ways to manage the aging processes consists in increasing the person's adaptability to the coming age-related changes. So, T.B. Gershkovich and N.S. Glukhanyuk (2003) mark such meaningfully efficient characteristic of activity as readiness for adoption of age-related temporal changes in the research of the process of human aging adaptation. The phenomenological analysis suggests that just the psychological readiness is that integrative characteristic, which includes all the above determinants of human subjective activity in the process of age-related temporal changes adoption.

In this context, the research of readiness for age-related changes adoption is a relevant and important task for both scientists in the field of general psychology and for practical psychologists.

Aim of the article is to research the particularities of coping strategies as determinants of psychological readiness for age-related changes adoption in people of various ages.

The modern psychological researches suggest that changes in stress response patterns occur with 
age (Boeninger, Shiraishi, Aldwin and Spiro, 2009). The literature states that energy reserves may become limited with age, so both middle-aged and senior people obviously need to develop more effective coping strategies that would allow them to spend less energy. It is noted that the level of daily stress decreases throughout the period from middle age to the end of life, despite health problems increasing, that means increasing of the coping efficiency, which consists in efforts for saving energy resources (Aldwin, Sutton, Chiara and Spiro, 1996). The theory of resources saving by S. Hobfoll (2001) states that the loss of resources is the basic component in the process of stress development, in contrast to the cognitive assessment. The neurophysiologic researches also indicate the coping activity decreasing with age. In particular, it was shown that the ultradian rhythm maintains sensitivity to stress factors. The picture may vary in frequency and amplitude and becomes disorganized in old age. It means that the body is less well prepared for dealing with stress factors (Sarabdjitsingh, Joels, DeKloet, 2012).

Certain researches are devoted to how the coping is associated with mechanisms of awareness by a person of own age. A.V. Kozar (2015) researched the coping behavior strategies and psychological readiness of late-maturity individuals for age-related changes adoption, on the basis of the Ukrainian population. She found that components of psychological readiness for age-related changes adoption created a small number of interrelations with the tendency of choosing constructive or destructive behavior coping strategies. The author proved that the most constructive coping strategy (assertive actions) was associated with a high level of readiness for age-related changes adoption, and she revealed that interrelations of other coping strategies with readiness for age-related changes adoption were contradictory; components and levels of readiness for age-related changes adoption did not form correlations with the general indicator of behavior coping constructiveness. Therefore, the specified contradictoriness requires a further research. Also, significant constraint consists in the fact that this research is focused on respondents aged from 58 to 64 years old, although the psychological readiness for age-related changes adoption is formed throughout the ontogenesis of person. However, attitudes to senior people and to old age in wider age intervals have not been sufficiently considered in literature, in general.

Accordingly, when conducting the research, we relied on the following theoretical and methodological backgrounds. According to our position, the coping strategies are important resource factors to form a person's readiness for age-related changes adoption; since the coping, generally, is an indispensable result of any stressful situation and basic factor that determines resistance to negative life events related, in particular, to the aging processes of a person.

\section{Methodology}

The research was carried out on the sample of 403 residents of four regions of Ukraine aged form 19 to 85 years old. The sample is intended to reflect particularities of the population of large cities in different parts of Ukraine, more specifically: Odesa (the Southern Ukraine), Kharkiv (the Eastern Ukraine), Kyiv (the Central Ukraine) and Lutsk (the Western Ukraine).

The special form was used for fixing results of the psychodiagnostic examination - the individual enquiry form, for researching and recording the data received. Diagnostics of psychological readiness for age-time changes adoption was carried out using the questionnaire of readiness for age-related changes (Glukhanyuk, Gershkovich, 2003). The method makes it possible to assess readiness formation for the coming various manifestations of old age, using the following scales: "General assessment of readiness formation for age-related changes adoption", "Physiological component", "Social component", "Personal-psychological component", "Professional component", "Cognitive level", "Affective level", "Motivational level". (It was decided in this research to determine the use of terms "readiness for age-related changes", "readiness for old age", "readiness for age-related changes adoption" in favor of the last one). The questionnaire of stressful situations coping strategies SACS (the Strategic Approach to Coping Scale) was used to research the coping peculiarities, which was recommended by S. Hobfoll with co-authors in 1993 (cited by: Vodopyanova, 2009). The questionnaire is based on his multiaxial model of "coping behavior". Unlike other models, the coping behavior is considered by him as strategies (trends) of behavior, but not as separate types of behavior. The model proposed has two main axes ("prosocial 
- asocial", "active - passive" and one additional axis "direct - indirect"). These axes represent measurements of the general coping strategies with correspondent following scales of the questionnaire: "Assertive actions", "Making social contact", "Search for social support", "Cautious actions", "Impulsive actions", "Avoidance", "Manipulative actions", "Asocial actions" and "Aggressive actions".

The multiple linear regression was a basic method of mathematical analysis. The regression analysis procedure with the simultaneous inclusion of all predictors (Keith, 2006) was used to detect the most significant predictors that determine the level of components of readiness for age-related changes that allowed using each other predictor as a control variable. Parameters of the SACS method were used as predictors. Parameters of readiness for age-related changes were used as response variables. Only statistically significant predictors were interpreted.

\section{Results}

The research findings showed that the following coping strategies: search for social support $(\beta=0.203 ; p=0.024)$, cautious actions $(\beta$ $=0.192 ; \mathrm{p}=0.039$ ) were statistically significant independent variables, when specifying the physiological component of readiness for agerelated changes adoption. Such predictors as assertive actions, making social contact, impulsive actions, avoidance, manipulative actions, asocial actions, aggressive actions are statistically insignificant. The determination coefficient for the entire regression model was $\mathrm{R}^{2}=0.032$, corrected determination coefficient for the entire model was $\mathrm{R}_{\mathrm{adj}}{ }^{2}=0.010$.

As provided for by the methodology of researching age-related changes, the physiological component of readiness includes understanding, tolerant attitude and ability to search for efficient ways of adoption to such manifestations of aging: loss of visual appeal, appearance of external signs of aging (wrinkles, gray hair, etc.), decreasing of visual acuity and hearing, increasing of fatigue, decreasing of sexual activity, dysfunction of cardiovascular and locomotor systems. Therefore, the search for social support as the coping strategy that characterizes the need for instrumental, emotional or informational assistance on the part of the environment, participates in formation of this readiness. This can be related to the fact that such individuals more frequently visit doctors and consequently are better prepared for physiological changes. In turn, the cautious actions are the coping strategy implemented in a prudent attitude towards own health and results in readiness for increasing the body's vulnerability, aging of basic physiological systems and manifestation of external signs of aging.

It was shown that the following predictors: making social contact $(\beta=0.199 ; \mathrm{p}=0.040)$, search for social support $(\beta=0.235 ; \mathrm{p}=0.009)$ were statistically significant predictors among the coping strategies to determine the social component of readiness for age-related changes adoption. Other independent variables were statistically insignificant. The determination coefficient for the entire regression model was $\mathrm{R}^{2}=0.029\left(\mathrm{R}_{\mathrm{adj}}^{2}=0.007\right)$.

According to the methodology, formation of the social component of readiness for age-related changes adoption enables a person to realize, accept and find ways to adapt for old age in the social sphere: this is an attitude of surrounding people as to a senior, old person, changes in the nature of communication with them; worsening of financial position and possession of "dependency" status; new social roles in the family: grandfather, grandmother; need for relations cultivation with social services. Consequently, making social contact and search for social support as two prosocial strategies, result in readiness for adoption of changes in attitude of others, changes in nature of communication, loss of old and acquiring new social roles.

It was noted that the following coping strategies: cautious actions $(\beta=0.188 ; p=0.040)$, avoidance $(\beta=-0.151 ; p=0.032)$ were statistically significant independent variables, when specifying the personal psychological component of readiness for age-related changes adoption. Other independent variables were statistically insignificant. The determination coefficient for the entire regression model was $R^{2}=0.056$ $\left(\mathrm{R}_{\mathrm{adj}}{ }^{2}=0.034\right)$.

The authors of methodology state that the personal-psychological component of readiness for age-related changes adoption is actualized in a person's ability to understand the mechanisms of psychological changes that occur to the person in the present or in the future; and, accordingly, treat them calmly as normality. This component helps the person to actively seek ways of compensation and self-regulation. The personal-psychological 
component considers the following changes: memory impairment, slowing deceleration of thinking process; tendency to share experience, teach, give advices; emotional overreaction to attitude of others, appearance of sense of "uselessness"; "sticking" to certain thoughts, details, affairs, experiences. Accordingly, the choice of using the coping strategy of cautious actions and reducing the use of the avoidance coping strategy indicates a "prudent involvement"; and, therefore, high level of volitional self-control that results in readiness for changes adoption in the cognitive sphere, tendency to share experience, vision of own place in the age structure.

It was shown that the following predictors: assertive actions $(\beta=0.169 ; p=0.024)$, making social contact $(\beta=0.222 ; p=0.017)$, search for social support $(\beta=0.292 ; p=0.010)$, avoidance $(\beta$ $=-0.219 ; p=0.001)$ were statistically significant predictors among coping strategies, when specifying the professional component of readiness for age-related changes adoption. The determination coefficient for the entire regression model was $\mathrm{R}^{2}=0.106\left(\mathrm{R}_{\mathrm{adj}}{ }^{2}=0.086\right)$.

Consequently, considering the professional component as a tolerant attitude to reduction of the role of professional activity in life and up to its loss, this component also covers the search and implementation of ways of self-expression in the non-professional sphere and contributes to adaptation to the following factors: competition with young colleagues and difficulties in mastering new working methods, new equipment; mastering the role of mentor in the professional activity or in the status of "former professional"; retirement, cessation of professional activities. Accordingly, the assertive and prosocial coping result potentially in successful adaptation to the role reduction of professional activity in life on retirement. In other words, intense involvement in interpersonal communication and efficient participation in social affairs are triggers for professional activity preservation in age-related changes.

It was noted that statistically significant independent variables, when specifying the cognitive level of readiness for age-related changes adoption were: cautious actions $(\beta=$ $0.185 ; p=0.046)$. The determination coefficient for the entire model was $R^{2}=0.032$ $\left(\mathrm{R}_{\mathrm{adj}}{ }^{2}=0.010\right)$.
The cognitive level indicates awareness and comprehension of age-related changes occurred, as well as knowledge of ways of their coping and mastering. The cognitive level of readiness for age-related changes adoption is determined by the coping strategy of cautious actions, indicating the key role in this self-regulation process.

The following coping strategies: making social contact $(\beta=0.225 ; p=0.018)$, search for social support $(\beta=0.301 ; p=0.001)$, avoidance $(\beta$ $=-0.140 ; \mathrm{p}=0.045$ ) were indicated as statistically significant independent variables, when specifying the affective level of readiness for age-related changes adoption. The determination coefficient for the entire regression model was $R^{2}=0.069$ $\left(\mathrm{R}_{\mathrm{adj}}{ }^{2}=0.048\right)$.

According to T.B. Gershkovich and N.S. Glukhanyuk (2003), the affective level is systemically important in the structure of readiness for age-related changes adoption; it acts as a link that mediates interrelations between the subject's awareness of expected future age-related changes and active searching for efficient strategies of adaptation to these changes. The high affective level of readiness means a tolerant attitude to the aging process (Yemelyanova and Zinina, 2015). Therefore, the prosocial coping strategies and involvement in interactions with stressors help persons investigated to reduce anxiety over loss of energy, independence, flexibility, sexuality, physical mobility, memory and intelligence.

It was demonstrated that the following indicators of the SACS questionnaire: assertive actions $(\beta=0.159 ; p=0.037)$, avoidance $(\beta=$ $0.214 ; p=0.002)$ were statistically significant independent variables, when specifying the motivational level of readiness for age-related changes adoption. The determination coefficient for the entire model was $R^{2}=0.074$ $\left(\mathrm{R}_{\mathrm{adj}}^{2}=0.053\right)$.

Therefore, the assertive coping is important for implementation of motivational readiness for age-related changes adoption, which ensures involvement in activities (in contrast to avoidance) and contributes to active searching and using of efficient strategies for age-related changes adoption. Such active involvement evidences the commitment of such persons to future. According to B.V. Biron (2015), the proactive and anticipatory-preventive coping are forms of coping that deal with future stressors. Consequently, the proactive and anticipatory- 
preventive attitude to old age enables the productive coping of age-related changes.

It was noted that following scales of the SACS questionnaire: making social contact $(\beta=0.193 ; p$ $=0.044)$, search for social support $(\beta=0.254 ; \mathrm{p}=$ $0.004)$, cautious actions $(\beta=0.181 ; p=0.048)$ were statistically significant independent variables, when specifying the general indicator of readiness for age-related changes adoption. The determination coefficient for the entire regression model was $\mathrm{R}_{2}=0.054\left(\mathrm{R}_{\mathrm{adj}}{ }^{2}=0.032\right)$.

So, understanding the specified indicator as an integral characteristic of readiness for age-related changes adoption, it is fair to state that, in general, this readiness is formed by the prosocial vector of coping strategies, which is guided by the processes of volition self-regulation. The age parameter was used as a control variable to test the stability of stated predictors in context of various age periods. In this regression model, the following coping strategies: search for social support $(\beta=0.136 ; p=$ $0.034)$ and avoidance $(\beta=-0.108 ; p=0.034)$ were statistically significant independent variables, when specifying the general indicator of readiness for age-related changes adoption. The determination coefficient for the entire regression model was $\mathrm{R}^{2}=0.514\left(\mathrm{R}_{\mathrm{adj}}{ }^{2}=0.502\right)$. In fact, the age parameter is characterized by a strong effect related to the general indicator of readiness $(\beta=$ 0.685 ; $\mathrm{p}<0.001$ ). Therefore, by eliminating the influence of age dynamics, it is fair to state that the coping acts as determinants of general readiness for age-related changes, characterizing an intense involvement in interpersonal communication and efficient participation in public life.

Therefore, considering the "readiness for agerelated changes adoption" in context of stress coping, we may conceptualize this notion as a social attitude of person to age-related changes in psycho, in physical state and in social environment as well. This is readiness for these changes adoption both in oneself and in others, using the most adaptive coping strategies for this: intensive involvement in interpersonal communication, efficient participation in public life, volition selfregulation. Consequently, the following dichotomy may be formulated: readiness for agerelated changes adoption is a positive attitude accompanied by the aforementioned efficient coping strategies. Unwillingness to adopt agerelated changes is considered as a negative attitude, which is characterized by inefficient coping strategies, specifically, stressor avoidance, retirement from social involvement and decreasing volition activity. That means that the concept of readiness for age-related changes serves as the use of efficient coping strategies in relation to the future image of own old age.

At the last stage of research, we compared the regression models in four age groups selected. The structure of regression models was characterized as follows: the indicators of coping strategies were predictors, and the general indicator of readiness for age changes adoption was resulting variable.

In the group of persons up to 34 years old, the following scales of the SACS questionnaire: making social contact $(\beta=0.326 ; p=0.043)$, search for social support $(\beta=0.439 ; p=0.002)$, avoidance $(\beta=-0.307 ; p=0.019)$ were statistically significant independent variables, when specifying the general indicator of readiness for age-related changes. The determination coefficient for the entire regression model was $\mathrm{R}^{2}=0.237 \quad\left(\mathrm{R}_{\mathrm{adj}}\right.$ $2=0.161)$.

In the age group of 35-41 years old, such SACS questionnaire scale as assertive actions $(\beta=$ $0.322 ; \mathrm{p}=0.050$ ) was used as statistically significant independent variables, when specifying the general indicator of readiness for age-related changes adoption. The determination coefficient for the entire regression model was $R^{2}=0.086$ $\left(R_{\text {adj }}^{2}=-0.023\right)$.

In the age group of 42-51 years old, such SACS questionnaire scale as making social contact $(\beta=0.445 ; p=0.053)$ was used as statistically significant independent variables, when specifying the general indicator of readiness for age-related changes adoption. The determination coefficient for the entire regression model was $R^{2}=0.077$ $\left(\mathrm{R}_{\mathrm{adj}}^{2}=-0.002\right)$.

And finally, among persons of age over 52 years old, such SACS questionnaire scale as avoidance $(\beta=-0.309 ; p=0.052)$ was used as statistically significant independent variable, when specifying the general indicator of readiness for age-related changes adoption. The determination coefficient for the entire regression model was $\mathrm{R}^{2}=0.082\left(\mathrm{R}_{\mathrm{adj}}{ }^{2}=-0.009\right)$.

So, it is found that the coping has the greatest influence in readiness formation for age changes adoption in the youngest age group under the age of 35 years old. During this age period, the activation of strategies of making social contact, search for social support and suppression of 
avoidance strategies play the most important role in ensuring the integral readiness. The role of coping strategies in determining readiness for agerelated changes adoption in other age periods is much less. So, in the age group of 35-41 years old, the coping strategy of assertive actions has the strongest effect; in the age group of people of 4251 years old - making social contact, these effects were positive. Among persons of age above 52 years old, the avoidance coping strategies have the strongest effect, but this effect is negative. That means that aging adoption contributes to constructive attitudes towards readiness for agerelated changes adoption.

\section{Discussion}

Determination in our research of the avoidance coping strategy as a negative predictor of readiness for age-related changes adoption corresponds to Ch. Walker's data that mature adults consider the acceptance of thoughts related to aging as a paradoxical tension. This tension intensifies and stabilizes the experience of transformational aging (Walker, 2002). It should also be noted that a proactive and anticipatorypreventive attitude to old age, established in the research, that enables efficient coping of agerelated changes, is confirmed in the work by M.O. Hogstel, L. Curry and Ch. Walker (Hogstel, Curry, Walker, 2005). Exploring the American population, the authors determined that those persons, who simultaneously care for both young children and senior parents, develop their own stability and use the coping mechanisms, because they anticipatorily see certain advantages associated with preparation for aging. In other words, since such persons see risks and benefits of aging, they actively use preventive and proactive actions for attendance provision in old age. The researchers found that adults who are more closely and sincerely involved in the life of parents in the aging process are better aware of the importance of such factors as choice of the way of living, ensuring successful and healthy aging.

\section{Conclusion}

In summary, the components and levels of readiness for age-related changes adoption are determined by a number of coping strategies that form the efficient core of stress coping, which indicate confirmation of the basic assumption of the research related to the coping strategies as a determinant of psychological readiness for agerelated changes adoption. Such strategies include assertive actions, making social contact, search for social support, cautious actions; conversely, the avoidance strategy forms a negative attitude towards age-related changes. These coping strategies are in generally characterized by the prosocial coping vector, which is guided by futureoriented processes. The age patterns were determined of readiness formation for age-related changes based on the coping strategies. It was demonstrated that the coping had the greatest influence on readiness formation for age changes adoption under the age of 35 years old. During this age period, activation of strategies of making social contact, search for social support, as well as suppression of avoidance strategies, play the most important role in ensuring the integral readiness. In other age periods the role of coping strategies in readiness determination for age-related changes adoption is significantly lower. The concept was formulated of readiness for age-related changes adoption as a social attitude to use adaptive coping strategies of person related to age-related changes in psycho, physical state and in social environment as well. The directions of future research consist in determination of individual psychological and social demographic determinants of readiness for age-related changes adoption.

Conflict of interest. We state that there is no conflict of scientific interests.

\section{References}

Biron B.V. (2015). Proaktyvne podolannia stresovykh sytuatsii osobystistiu [Proactive overcoming of stress situations by $\mathrm{p}$ ersonality] Candidate's thesis. Odessa: Odessa I.I. Mecnikov National University [in Ukrainian].

Vodopianova, N.E. (2009). Psikhodiagnostika stressa [Psychodiagnosis of stress]. SanktPeterburg: Piter [in Russian].

Voroshilova, I.I. (2008). Ozhidaemaia prodolzhitelnost zhizni i smertnost kak indikatory kachestva zhizni pozhilykh liudei. Sovremennye naukoemkie tekhnologii [Expected life-

span and death rate as indicators of quality of life of elderly people. Modern scientific techno logies] Vol. 6, 38-39 [in Russian].

Glukhaniuk N.S. \& Gershkovich T. B. (2003). Pozdnii vozrast i strategii ego osvoeniia [Late age and strategies of his mastering]. Moskva: MPSI [in Russian]. 
Emelianova T.P. \& Zinina A.A. (2015). Atributsiia otvetstvennosti za psikhologicheskoe blagopoluchne prestarelykh liudei $\mathrm{v}$ predstavleniiakh studencheskoi molodezhi i rabotaiushchikh vzroslykh [Attribution of responsibility for psychological prosperity of the aged people in presentations of student young people and working adults. $\mathrm{K}$ nowledge. Understanding. Ability]. Znanie. Ponimanie. Umenie/ Vol.2, 260-269. [in Russian].

Kotsar A. V. (2015). Stratehii kopinh povedinky ta psykholohichna hotovnist osib viku piznoi zrilosti do pryiniattia vikovykh zmin [Strategies of coping behavior and psychological readiness of persons

age of late maturity are to the acceptance of ag e-old changes]. Visnyk Kharkivskoho natsionalnoho universytetu imeni $V . \quad N$. Karazina. Seriia: Psykholohiia [Announcer of V. N. Karazin Kharkiv National University. Ser.: Psychology], no.1150 (57), 15-20. [in Ukrainian].

Kremenchutska M.K. (2013). Ekzystentsialni perezhyvannia $\mathrm{v}$ litnomu vitsi [Existential experiences in old age].

Nauka i osvita [Science and education], 7 (CYXI), 48-52. [in Ukrainian].

Aldwin, C.M., Sutton, K.J., Chiara, G. \& Spiro, A. (1996) AgeDifferencesinStress, Coping, and Appraisal: Findings from the Normative Aging Study. Journal of Gerontology: Psychological Sciences, 51, 179-188.

Boeninger, D. K. ,Shiraishi , R. W., Aldwin , C. M. , \&Spiro , A. ( 2009 ). Why do older men report low stress ratings? Findings from the Veterans Affairs Normative Aging Study. International Journal of Aging and Human Development, 68 ( 2 ), 149 - 170 .

Hogstel, M. O., Curry, L. C., \&Walker, C. (2005). Caring for older adults: The benefits of informal family caregiving. Journal of Theory Construction \& Testing, 9, 55.

Sarabdjitsingh, R. A., Joels, M. \& DeKloet, E. R. (2012). Glucocorticoid pulsatility and rapid corticosteroid actions in the central stress response. Physiology and Behavior 106, 73-80. 